\title{
Alpha-GST Excretion Rate
}

National Cancer Institute

\section{Source}

National Cancer Institute. Alpha-GST Excretion Rate. NCI Thesaurus. Code C119278.

A determination of the amount of alpha glutathione-s-transferase being excreted over a defined period of time. 